\title{
Variation in the pelvic and pectoral girdles of Australian Oligo-Miocene mekosuchine crocodiles with implications for locomotion and habitus
}

\author{
Michael D Stein ${ }^{\text {Corresp., }}{ }^{1}$, Adam Yates ${ }^{2}$, Suzanne J Hand ${ }^{1}$, Michael Archer ${ }^{1}$ \\ 1 PANGEA Research Centre, School of Biological, Earth and Environmental Sciences, University of New South Wales, Sydney, New South Wales, Australia \\ 2 Museum of Central Australia, Alice Springs, Northern Territory, Australia \\ Corresponding Author: Michael D Stein \\ Email address: michael.stein@student.unsw.edu.au
}

Australian Oligo-Miocene mekosuchines (Crocodylia; Crocodyloidea) display wide diversity in cranial shape and inferred hunting strategies. Terrestrial habitus has been inferred for these distinctive predators. A direct morphological signal for locomotion can be expected in the postcrania, particularly the pelvic and pectoral girdles. Here we describe fossil materials of the girdles, which chart their morphological variation in the subfamily from Eocene through to Middle Miocene. Over this period, both girdles undergo significant morphological changes. Notably, an enclosed, ventrally orientated acetabulum in the ilium is developed in one lineage. This recapitulates the erect parasagittal configuration of the pelvic limb seen in many Mesozoic crocodylomorph lineages, suggesting consistent use of erect high-walking in these mekosuchines. Other pelves from the same Oligo-Miocene deposits display morphology closer to modern crocodilians, suggesting a partitioning of locomotory strategy among sympatric mekosuchines. Plesiomorphic and derived pelvic girdles are distinguishable by parsimony analysis, and the earliest examples of the mekosuchine pelvis more closely resemble gavialids and alligatorids while latter forms converge on crown group crocodylids in the morphology of the iliac crest. This suggests that a revaluation of the base relationship of Mekosuchinae within Eusuchia is necessary. 


\section{Variation in the pelvic and pectoral girdles of Australian Oligo-Miocene}

\section{2 mekosuchine crocodiles with implications for locomotion and habitus}

3 Michael D Stein ${ }^{1}$, Adam Yates ${ }^{2}$, Suzanne J Hand ${ }^{1}$, and Michael Archer ${ }^{1}$

$4{ }^{1}$ PANGEA Research Centre, School of Biological, Earth and Environmental Sciences,

5 University of New South Wales, Sydney, New South Wales, Australia

$6 \quad{ }^{2}$ Museum of Central Australia, 4 Memorial Avenue, Alice Springs, Northern Territory, Australia

8 Corresponding Author

9 Michael Stein ${ }^{1}$

10 PANGEA Research Centre, School of Biological, Earth and Environmental Sciences, University

11 of New South Wales, Sydney, New South Wales 2052, Australia

12 Email: michael.stein@student.unsw.edu.au 


\section{Abstract}

25 Australian Oligo-Miocene mekosuchines (Crocodylia; Crocodyloidea) display wide diversity in cranial shape and inferred hunting strategies. Terrestrial habitus has been inferred for these

27 distinctive predators. A direct morphological signal for locomotion can be expected in the 28 postcrania, particularly the pelvic and pectoral girdles. Here we describe fossil materials of the 29 girdles, which chart their morphological variation in the subfamily from Eocene through to 30 Middle Miocene. Over this period, both girdles undergo significant morphological changes.

31 Notably, an enclosed, ventrally orientated acetabulum in the ilium is developed in one lineage.

32 This recapitulates the erect parasagittal configuration of the pelvic limb seen in many Mesozoic crocodylomorph lineages, suggesting consistent use of erect high-walking in these mekosuchines. Other pelves from the same Oligo-Miocene deposits display morphology closer to modern crocodilians, suggesting a partitioning of locomotory strategy among sympatric mekosuchines. Plesiomorphic and derived pelvic girdles are distinguishable by parsimony analysis, and the earliest examples of the mekosuchine pelvis more closely resemble gavialids and alligatorids while latter forms converge on crown group crocodylids in the morphology of the iliac crest. This suggests that a revaluation of the base relationship of Mekosuchinae within Eusuchia is necessary.

\section{Introduction}

43 A common perception of crocodilians is that they are morphologically conservative and in this

44 sense modern crocodilians are sometimes thought of as 'living fossils'. In fact, however, the fossil record documents that crocodylomorphs underwent a morphologically dynamic radiation following divergence of the Pseudosuchia (crocodile-line archosaurs) from the Avemetatarsalia 
47 (pterosaurs, dinosaurs and birds) 245-249 million years ago [Ma] (Markwick, 1998; Reilly \&

48 Elias, 1998; Brochu, 2003; Brusatte et al., 2008; Sereno \& Larsson, 2009; O'Connor et al., 2010;

49 Oaks, 2011; Stubbs et al., 2013; Toljagic \& Butler, 2013; Mannion et al., 2015; Wilberg 2017).

50 Comparisons of the pelvic girdles in crocodilians, dinosaurs and birds have been the subject of

51 several studies on the evolution of locomotion in these groups (Romer, 1923a; Romer, 1923b;

52 Parrish, 1987; Gatesy, 1991; Meers, 2003; Hutchinson, 2006; Irmis, 2007; Abdala \& Diogo,

53 2010; Schachner, Manning \& Dodson, 2011; Chamero, Buscalioni \& Marugan-Lobon, 2013).

54 Current consensus holds that a semi-aquatic habitus was adopted sporadically among Mesozoic

55 crocodylomorphs, and definitively in eusuchians by the Late Cretaceous (Parrish, 1987;

56 Hutchinson, 2006). Like all aquatic amniotes, eusuchians returned to the water rather than

57 emerged from it, a fact reflected in their morphology (Parrish, 1986; Parrish, 1987; Sereno, 1991;

58 Reilly \& Elias, 1998). Because lacustrine and fluvial environments are more conducive to

59 preservation than most terrestrial habitats, there is a taphonomic bias towards semi-aquatic forms

60 in the fossil record. This, coupled with the dominance of a semi-aquatic habitus in extant

61 crocodilian faunas, has led to this common perception that crocodiles as a whole have

62 maintained a relatively conservative body form, a perception that reflects the presumption that

63 most have occupied more or less similar freshwater lactustrine/fluviatile habitats (Brochu, 2003).

64 Throughout their history, however, there are also examples of purely terrestrial and marine

65 crocodylomorphs (Colbert, 1946; Buckley et al., 2000; Schwarz, Frey \& Martin, 2006; Sereno \&

66 Larsson, 2009; O’Connor et al., 2010; Sertich \& Groenke, 2010; Pol et al., 2012; Puertolas-

67 Pascual et al., 2016).

68 
69 Australian mekosuchine crocodiles developed a wide variety of cranial morphologies indicative

70 of varied hunting strategies in the Oligo-Miocene (Hecht \& Archer, 1977; Willis, Murray \&

71 Megirian, 1990; Megirian, Murray \& Willis, 1991; Willis \& Molnar, 1991; Willis, 1993; Willis,

72 Molnar \& Scanlon, 1993; Megirian, 1994; Salisbury \& Willis, 1996; Willis, 1997a; Willis,

73 1997b; Willis, 2001; Molnar, Worthy \& Willis, 2002; Willis \& Molnar, 2008; Stein, Hand \&

74 Archer, 2016). This includes indications of a more terrestrial lifestyle. Species of Quinkana,

75 Mekosuchus and possibly Trilophosuchus display lateralization of orbits and nares (Willis, 1993;

76 Megirian, 1994). Quinkana is further characterised by mediolateral compression of the rostrum

77 and serrate labiolingually compressed (ziphodont) teeth, a trait associated more closely with

78 active cursorial hunting than the ambush strategies ubiquitous in large-bodied extant crocodilians

79 (Colbert, 1946; Megirian, Murray \& Willis, 1991; Megirian, 1994; Pol et al., 2012).

80

81 A shift towards a more terrestrial habitus during the Oligo-Miocene should be reflected in

82 anatomical features relating to locomotion such as in the limbs, pectoral and pelvic girdles.

83 Previous work has examined the early mekosuchine forelimb (Stein et al., 2012). Fossil material

84 of the pectoral and pelvic girdles has been recovered from sites across northern Australia. These

85 specimens allow an overview of the evolution of locomotion of mekosuchines from the Eocene

86 to Middle Miocene, with comparisons revealing significant morphological changes over this

87 period. The present paper describes these changes and their implications for locomotory

88 behaviours during the zenith of mekosuchine diversity.

89

90 Materials \& Methods 
91 Fossils representing the pectoral and pelvic girdles of mekosuchine crocodiles were collected

92 from Cenozoic localities in both Queensland and the Northern Territory (Fig. 1). Queensland

93 localities include Tingamarra near the township of Murgon, and The Narrows Graben near

94 Gladstone, located in the southeast and central east of the state respectively, and the Riversleigh

95 World Heritage Area located in the northwest. The Tingamarra Local Fauna (LF; sensu Archer et

96 al., 1989) is regarded as Early Eocene in age (Godthelp et al., 1992), while The Narrows Graben

97 preserves the Rundle LF, regarded as Late Eocene in age (Henstridge \& Missen, 1982).

98 Crocodiles in the Riversleigh LF's range in age from Late Oligocene to modern (Archer, Hand \&

99 Godthelp, 1991), with Oligo-Miocene assemblages grouped as Faunal Zones A-D (Travouillon

100 et al., 2006) recovered from freshwater carbonates referred to respectively as Depositional

101 Phases 1-4. Faunal Zone A is interpreted to be Late Oligocene in age, Zone B as Early Miocene,

102 Zone C as Middle Miocene and Zone D as possibly early Late Miocene (Woodhead et al., 2016).

103 Northern Territory localities include Bullock Creek, on Camfield Station, and Alcoota Station,

104 near Alice Springs, located in the northwest and south of the territory respectively. The Bullock

105 Creek LF is regarded as a Middle Miocene contemporary of Riversleigh's Faunal Zone C (Black

106 et al., 2012) while the Alcoota LF is regarded as Late Miocene in age (Megirian et al., 2010).

107 Institutional abbreviations: QM, Queensland Museum; NMV, Museum Victoria; NTM, Northern

108 Territory Museum; AM, Australian Museum. Anatomical terms, illustrated in Figure 2, follow

109 Pol et al. (2012).

110

111 To place the mekosuchine pelvic girdle into a phylogenetic context, iliac materials were scored

112 according to character states modified in part from Brochu (1999), detailed in Appendix 1. One

113 specimen, QM F57910, was excluded as the majority of characters could not be scored. 
114 Parsimony analysis of the resulting matrix (Appendix 2) was undertaken in PAUP 4.0 (Swofford,

115 2003). Maximum parsimony topographies were generated by the two step method used by

116 Worthy et al. (2006) and performing 1000 replicates at the initial step. As the most basal

117 eusuchian taxon available for scoring, Gavialis gangeticus (Gmelin, 1789) was used as the

118 outgroup to the Crocodylidae in which the Mekosuchinae currently nest (Brochu 2003). The

119 integrity of the selected character matrix was further tested using a bootstrap analysis of 1000

120 replicates. Nexus format files of the data are provided as supplementary materials.

122 Tingamarra, Queensland. QM F57908, right ilium; QM F57909, right ilium; QM F57910, left

123 ilium; QM F54537, right ischium; QM F54533, right coracoid; QM F23586, left coracoid.

125 The Narrows Graben, Queensland. NMV P228164, right ilium; NMV P228627, right ilium;

126 NMV P228635, left ilium; NMV P252361, left ilium; NMV P228615, right pubis; NMV

127 P228623, right scapula; NMV P252360, right scapula; NMV P227038, left scapula; NMV

128 P227803, left scapula; NMV P252359, right scapula and partial coracoid.

129

130 Riversleigh World Heritage Area, Queensland. Zone A. Quantum Leap Site: QM F41198, left

131 ilium. Zone B. Price is Right Site: QM F57913, partial pelvis in articulation; QM F57914, first

132 sacral vertebrae; QM F57912, right coracoid. Zone C. Golden Steph Site: QM F31406, right

133 ilium; Ringtail Site: QM F40581, right ilium; QM F57911, right ilium.

134

135 Bullock Creek, Northern Territory. NTM P891-5, left ilium; NTM P908-35, left ilium; NTM

136 P8695-272, right ischium; NTM P906-23, right ischium; NTM P895-139, right coracoid. 
138 Alcoota Station, Northern Territory. NTM P5895, left ilium.

\section{Results}

141 Parsimony analysis. 282 trees of 18 steps were generated. Specimens consistently organise into

142 three clades, with a fourth in basal polytomy with the Gavialis outgroup (Fig. 3A), reflecting

143 apparent generic or specific grouping. For the rest of this paper the term pelvic form is used to

144 refer to these groups and the morphology of ilia and associated materials is subsequently

145 discussed within this framework. These pelvic forms also display a consistent placement, pelvic

146 forms three and four grouping as the most derived and form two placing basal to these. There is

147 strong bootstrap support for the pelvic forms (Fig. 3B), but the relationships between forms is

148 supported only insofar as forms three and four group more closely with respect to forms one and 149 two.

150

151 Pelvic Form One. Right ilium QM F57908 (Figs. 4A-C), right ilium QM F57909 (Fig. 4D), left

152 ilium QM F57910 (Fig. 4E), and right ischium QM F54537 (Figs. 4F-H). The postacetabular

153 process of the ilium is robust, dorsoventrally taller than the short ischial and pubic peduncles and

154 bluntly terminating in the posteriorly orientated articular surface of the M. ilioischio caudalis.

155 The iliac crest expands dorsally, $30-40^{\circ}$ from the sagittal plane. The articular surface of the

156 pubic peduncle is orientated anteroventrally. The margin of the acetabular perforation between

157 ischial and pubic peduncles is small and well defined. The acetabulum is shallowly concave.

158 Attachment sites for the transverse processes of the sacral vertebrae are situated centrally on the 159 ilium's medial surface. 
161 The ischium is similarly robust. The preserved extent of the distal blade displays very little

162 medial curvature. The posterior extension of the ischial arch is pronounced, reaching nearly

163 twice the length of the proximal condyles. The anterior extent of the blade forms a thick, rugose

164 margin. The muscle scar of the M. puboischio tibialis on the lateroanterior surface of the blade

165 (Fig. 4F) is well developed.

166

167 Pelvic Form Two. Right ilium NMV P228164 (Figs. 5A-C), left ilium NMV P228635 (Fig. 5D),

168 left ilium, NMV P252361 (Fig. 5E), right ilium NMV P228627 (Fig. 5F), right ilium QM

169 F40581 (Fig. 5G), and right pubis NMV P228615 (Fig. 5H). The postacetabular process of the

170 ilium is larger compared to pelvic form one, both anteroposteriorly elongate and dorsoventrally

171 deep. The iliac crest orientates $30-40^{\circ}$ from the sagittal plane similar to pelvic form one and

172 forms a prominent convex arch just posterior to the ischial peduncle. Consequently the

173 preacetabular process is situated between concave margins on the iliac crest. The attachment for

174 the M. ilioischio caudalis forms a posteriorly extending terminal knob distinct from the margin

175 of the iliac crest (Figs. 5A, 5D, 5E-F). The pubic and ischial peduncles are more developed than

176 those displayed by pelvic form one, proportionally deep even in relation to the expanded

177 postacetabular process. Similar to pelvic form one however, the acetabulum is shallowly

178 concave, the pubic peduncle is anteroventrally orientated and the perforation between peduncles

179 is well defined. Attachment scars for the sacral vertebrae are situated centrally on the medial

180 surface of the ilium. QM F40581 is similar in profile but with a less developed terminal knob

181 (Fig. 5G). The pubis is expanded mediolaterally, displaying a well-developed medial condyle

182 and pronounced rugosities on the dorsolateral surface of the distal blade. 
184 Pelvic Form Three. Left ilium QM F41198 (Figs. 6A-C), right ilium QM F57911 (Fig. 6D), left

185 ilium NTM P908-35 (Fig. 6E), left ilium NTM P891-5 (Fig. 6F), left ilium NTM P5895 (Fig.

186 6G), right ischium NTM P906-23 (Fig. 6H), and right ischium NTM P8695-272 (Fig. 6I). The

187 preacetabular process is situated towards the anterior of the iliac crest, encroaching onto the

188 pubic peduncle. The postacetabular process is gracile compared to pelvic forms one and two,

189 dorsoventrally shallower than the deep ischial and pubic peduncles, and bluntly terminates in the

190 posterodorsally orientated articular surface of the M. ilioischio caudalis. The iliac crest displays

191 a slight lateral expansion, orientating $40-60^{\circ}$ from the sagittal plane. The pubic peduncle

192 expands anteriorly such that it is level with the ischial peduncle. The iliac portion of the

193 acetabulum is nearly imperforate in consequence, the margin between peduncles not greatly

194 penetrating into the acetabular space. The acetabulum is deeply concave. The attachments for the 195 sacral vertebrae are situated centrally on the medial surface of the ilium.

197 The distal blade of the ishium (Figs. 6H, I) does not expand as posteriorly as that of pelvic form 198 one, being closer in proportion to the columnar blade of modern crocodilians. The distal blade is 199 also more gracile than in pelvic form one, lacking the thick anterior margin and prominent 200 rugosity. Despite reduction of the iliac margin of the acetabular perforation, the ischial margin is 201 well defined by the bridge of the ischial peduncles.

203 Pelvic Form Four. Partial left pelvis QM F57913 (Figs. 7A-E) and right ilium QM F31406 (Fig.

204 7F). The postacetabular process is dorsoventrally deep and both iliac crest and postacetabular

205 process expand laterally $60-70^{\circ}$ from the sagittal plane, enclosing a deeply concave acetabulum 
206 dorsally (Fig. 7C). The articular surface for the M. ilioischio caudalis forms a posterodorsally

207 facing rim, distinctly raised from the margin of the iliac crest (Figs. 7A, F). The dorsal rugosity

208 of the iliac crest is well developed. Sites for the attachment of the transverse processes of the

209 sacral vertebrae are situated ventrally on the medial surface of the ilium. The transverse process

210 of the posterior sacral vertebrae is entirely excluded from the ventral margin of the

211 postacetabular process and confined to the ischial peduncle. The attachment of the anterior sacral

212 vertebrae has shifted anteroventrally with the preacetabular process, such that a distinct space

213 now separates both attachment sites. As a consequence, the medial surface of the iliac crest is

214 larger compared to the other pelvic forms and a large portion of the posterior iliac crest would

215 have extended beyond the sacral vertebrae. Similar to pelvic form three, the ischial peduncle is

216 proportionally deep compared to the shallow postacetabular process, with a mediolaterally wide

217 and anteroposteriorly compressed articular face that forms a broad triangular surface which

218 encloses the acetabulum posteriorly. The transverse process preserved on the first sacral

219 vertebrae QM F57914 (Fig. 7G) is mediolaterally compact in proportion and anteroposteriorly

220 compressed into a curved subquadrate lamina of bone displaying little posterior extension of the

221 kind typically seen in modern crocodilians. This corresponds to the attachment sites displayed by

222 pelvic form four.

223

224 The ischium is similar in proportions to that of pelvic form one, displaying an anteroposteriorly

225 expansive distal blade that is wider than the proximal head. The blade is gracile, however,

226 similar to pelvic form three. The anterior peduncle is expanded, forming a broad ovoid ventral

227 margin to the acetabular perforation. The head of the anterior peduncle is anteroposteriorly

228 compressed, forming an enclosed anterior wall of the acetabulum. The posterior peduncle is 
229 similarly anteroposteriorly wide, with a mediolaterally expanded anterior margin that articulates

230 with the posterior peduncle of the ilium to enclose the acetabulum posteriorly. The pubis is

231 gracile, anteroposteriorly elongate and displays only slight ventral curvature in medial view.

232

233 Pectoral Girdle Material. Left coracoid QM F23586 (Fig. 8A), right coracoid QM F54533 (Fig.

234 8B), left scapula NMV P227803 (Fig. 8C), and right scapula NMV P252360 (Fig. 8D). The

235 scapula and coracoid are moderately robust elements in these specimens, the distal blade of the

236 coracoid being approximately twice the depth of the proximal head and the diaphysis greater

237 than half the width of the proximal head and distal blade. The anterior process of the proximal

238 head is anteroposteriorly short and blunt.

240 Right coracoid NTM P895-139 (Fig. 8E). This specimen is a very robust element. The distal

241 blade is short compared to the other specimens, about equal to the proximal head in dorsoventral 242 depth, and separated by a robust bridge about half the length of the proximal head. The anterior 243 process is short and blunt.

245 Left scapula NMV P227038 (Fig. 8F), right scapula NMV P228623 (Fig. 8G), right scapula and 246 partial coracoid NMV P252359 (Fig. 8H), and right coracoid QM F57912 (Fig. 8I). Both scapula

247 and coracoid are elongate and gracile elements in these specimens. The distal blade of the 248 scapula is approximately two and a half times the length of the distal head and the diaphysis is 249 less than half the width of the distal blade in both coracoid and scapula. The articular surface of 250 the glenoid fossa in the coracoid is anteroposteriorly wide, more so than the glenoid displayed by 
251 the other specimens. Both scapula and coracoid display expansive and acute anterior processes of

252 the glenoid joint.

253

254 Discussion

255 Fossils described here afford an opportunity to examine changes in the mekosuchine pelvic

256 girdle during the early to middle Cenozoic. Pelvic form one appears to be representative of a

257 species of Kambara, having been collected in association with skulls referable to that genus at

258 Tingamarra. This includes QM F57910, suggesting this specimen pertains to pelvic form one

259 rather than two, despite its fragmentary state. These Early Eocene fossils represent the oldest

260 mekosuchine materials known and potentially shed light on what could be plesiomorphic

261 features in mekosuchines. In form one, the ilium is robust, resembling gavialids and alligatorids

262 in general morphology, with proportionally shallow ischial and pubic peduncles, shallowly

263 concave acetabulum, and rounded postacetabular process that displays little of the dorsal

264 constriction typical of crown group crocodylids (Figs. 2, 4A, 4D) (Brochu, 1999). This is notable

265 in itself, suggesting an earlier radiation of mekosuchines within the Crocodylia than indicated by

266 phylogenies based on crania, which place Mekosuchinae within the Crocodylidae (Salisbury \&

267 Willis, 1996; Brochu, 2003). In most other respects the ilium resembles the typical eusuchian

268 system, displaying an acetabulum and iliac crest orientated in the sagittal plane and sacral

269 articulation centrally situated on the medial face (Figs. 4B-C) (Brochu, 1999).

270

271 Significant differences in the acetabulum and iliac crest can be seen in pelvic form two, known

272 from the Late Eocene, and shared with Oligo-Miocene pelvic forms three and four. The

273 acetabulum in these forms is characterised by increasing peduncle depth and, in the Oligo- 
274 Miocene forms, concavity. In all Oligo-Miocene forms, the ischial peduncle increases in

275 proportional depth to the iliac crest, deepening the pelvis overall (Figs. 5A, 6A, 7A). Pelvic form

276 three (Figs. 6A, 6D-F) displays anteroventral expansion of the pubic peduncle, which reduces

277 the extent of the iliac portion of the acetabular perforation. The pelvic girdle remained perforate

278 in mekosuchines, evidenced by the ischia described here (Figs. 6H-I, 7A). The anterior extent of

279 pelvic form four is unknown but marked anterior expansion of the pubic peduncle in the ischium 280 suggests a similar morphology to pelvic form three (Fig. 7A). Both pelvic forms three and four

281 display increasing concavity of the acetabular space (Figs. 6A, 6D-G, 7A). Pelvic form two, by

282 contrast, does not display expansion of the pubic peduncle and remains only slightly concave in

283 Oligo-Miocene taxa (Figs. 5A, 5G).

284

285 This same division between pelvic form two and forms three and four is apparent in the changes 286 of the iliac crest, characterised by development of a distinct terminal knob on the postacetabular 287 process, evidently convergent on but not identical with the constriction seen in crown group 288 crocodylids (Brochu, 1999), and expansion of the crest itself. Unlike the crocodylid constriction,

289 the terminal knob in pelvic form two appears to develop by a posteriorly orientated expansion of

290 the iliac crest (Figs. 5A, 5D-F). In pelvic form three the expansion has become pronounced

291 enough to subsume the postacetabular process, but in contrast to pelvic form two is now

292 posterodorsally orientated (Figs. 6A, 6E), and occurs as a dorsal rim in pelvic form four (Fig.

293 7F). Pelvic form two displays a dorsally expansive iliac crest similar to pelvic form one (Fig. 5A,

294 5D). The crest of pelvic form three is somewhat ambiguous, displaying slight lateral expansion

295 (Fig. 6C) but the same sacral articulation as forms one and two. The crest is greatly modified in 296 pelvic form four, enclosing the acetabulum dorsally, while the laterally expansive pubic and 
297 ischial peduncles enclose the acetabulum anteroposteriorly (Fig. 7C). Pelvic form three is

298 associable with crania of Baru darrowi (Willis, Murray \& Megirian, 1990) in the Bullock Creek

299 LF. The highly modified morphology of the ilium in pelvic form four suggests affinity with the

300 similarly highly derived Quinkana meboldi (Willis, 1997b) of Riversleigh's Miocene faunas, but

301 associated materials will be necessary to confirm this. Ontogeny is another possible explanation

302 for the close resemblance between pelvic forms three and four, although dissimilar sacral

303 articulation and iliac crest development across a range of sizes suggest they represent different

304 taxa rather than different developmental stages within one species.

305

306 These different morphologies of the pelvic forms, together with their relative ages, suggest

307 separate successive radiation events corresponding to the climatic optima of the Eocene and

308 Miocene, a common trend observed in many early Cenozoic crocodilian communities (Brochu,

309 2003; Mannion et al., 2015). Buchanan (2009) observed that the well diversified Miocene

310 radiation of mekosuchines is likely to have been derived from an Eocene radiation restricted to

311 the Australian continent. It is possible pelvic form two represents a separate species of Kambara,

312 with diversification in the genus more conspicuous in the postcrania than crania. However,

313 pelvic form two persists into Oligo-Miocene Riversleigh faunas, from which Kambara has not

314 been reported. It is more likely that pelvic form two represents a different genus, suggesting

315 greater generic diversity in the Eocene than is reflected in known skull forms. The Oligo-

316 Miocene presence of pelvic form two, coupled with the fact that none of NMV P228164, NMV

317 P228635, NMV P252361, NMV P228627 or QM F40581 are greater than five centimetres in

318 antero-posterior length, suggests it may represent Mekosuchus, a genus of suspected dwarf

319 species (Willis, 1997b), although this remains speculation until skeletal association with the 
320 cranium can be made. If such is the case, these ilia would push the origins of Mekosuchus and

321 tribe Mekosuchini earlier into the Eocene.

322

323 These interpretations are supported by the results of the parsimony analysis that generally places

324 pelvic forms one and two basal to forms three and four, in agreement with their relative ages

325 (Fig. 3A). Because the mekosuchine pelvis cannot be distinguished on the basis of a strict

326 apomorphy, and appears to have developed the constriction of the postacetabular process of

327 crown group crocodylids convergently, any parsimony analysis is likely confounded by some

328 degree of homoplasy. The effect of this can been seen in the loss of tree resolution under

329 bootstrap analysis, although the later Oligo-Miocene forms remain distinct (Fig. 3B). Coupled

330 with the more gavialid/alligatorid features displayed by pelvic form one, this warrants

331 revaluation of the base relationships of the Mekosuchinae within the Eusuchia. While this falls

332 beyond the scope of the present paper, work in preparation by one of us (AY) aims to revaluate

333 mekosuchine taxonomic relationships within a more robust phylogenetic framework than

334 previously available.

335

336 The lateral expansion of the iliac crest, accompanied by ventral migration of the transverse

337 processes of the sacral vertebrae in pelvic form four is the most conspicuous development of the

338 mekosuchine pelvis, with substantial effect (Figs. 7B-C). First, this arrangement increases the

339 medial and lateral surface area of the iliac crest. Second, it re-orientates the acetabulum

340 ventrolaterally, with much of the dorsal extent of the acetabulum effectively facing ventrally.

341 Third, the postacetabular process extends further posterior to the sacral vertebrae compared to

342 the situation in modern crocodilians. This highly derived morphology is remarkable in its 
343 similarity to the girdle reported in sebecosuchians (Colbert, 1946). The iliac crest of the

344 terrestrial South American Eocene Sebecus icaeorhinus (Simpson, 1937) displays similar lateral

345 orientation and expansion and ventral migration of the transverse processes of the sacral

346 vertebrae (Pol et al., 2012). When mekosuchines were first described, a possible relationship

347 with Paleogene sebecosuchians was suggested (Hecht \& Archer, 1977; Megirian, 1994). Willis

348 (1993) established Mekosuchinae as a subfamily within Eusuchia and attributed their similarity

349 to sebosuchians to evolutionary convergence. This appears also to be the case for postcrania. The

350 earliest (and perhaps least derived) form of the mekosuchine ilium bears little resemblance to

351 that seen in the contemporaneous S. icaeorhinus.

352

353 This convergent morphology suggests pelvic form four was similarly adapted for pillar-erect

354 stance, as Pol et al. (2012) infers occurred in S. icaeorhinus. Erect pelvic stance has evolved

355 independently several times in amniotes by way of two systems (Benton \& Clark, 1988;

356 Schachner, Manning \& Dodson, 2011). The first, buttress-erect case characterises the bird-line

357 archosaurs and mammals. The proximal femur has a medial head or ball which articulates with a

358 defined socket on the pelvic girdle, and lateral trochanters allowing the limb to operate in a

359 sagittal arc of motion while maintaining an effective line of action for the pelvic musculature by

360 its insertion onto the trochanter. The second, pillar-erect case characterises the bulk of early

361 archosaurs and Mesozoic crocodylomorphs (Parrish, 1987; Sereno, 1991). Instead of the femur

362 being modified, the pelvis is laterally expanded. This results in articulation of the limb in a

363 ventral position, again allowing a sagittal arc of motion while maintaining an effective line of

364 action for the appendicular musculature from their origins now situated over the limb. 
366 Pelvic form four appears to show modifications towards the pillar-erect case. The lateral

367 reorientation of the iliac crest shifts the origins for much of the dorsal medial musculature of the

368 ilium dorsolaterally with respect to the proximal head of the femur. Affected musculature

369 includes many of the main abductors and flexors of the hind-limb involved during the stance

370 phase of the step cycle. These include the M. ilio-femoralis, M. ilio-tibialis, M. ilio-fibularis, $M$.

371 femero-tibialis externus, the dorsal branch of the M. femero-tibialis internus and the M. ilio-

372 costalis (Romer, 1923a; Romer, 1923b; Hutchinson \& Gatesy, 2000). The effect would be to

373 increase the lever arm of these muscles to the femur when held near the sagittal plane, similar to

374 the effect of the greater trochanter in erect stance in mammals (Benton \& Clark, 1988).

375

376 This has consequences for postural range, however. Among eusuchians, various postures are

377 adopted during locomotion, ranging from lateral sprawling to an erect high-walk and gallop

378 (Benton \& Clark, 1988; Reilly \& Elias, 1998; Hutchinson \& Gatesy, 2000). Kinematics between

379 postures are identical, postural grades differing only in the orientation of the femur (Reilly \&

380 Elias, 1998). Freedom of orientation is enabled by the open planar surface of the acetabulum and

381 accompanying lateral muscular origins on the iliac crest, which afford a significant line of action

382 to the limb musculature across a wide arc (Reilly \& Elias, 1998). Pelvic forms one and two are

383 similar to this basal eusuchian system and hence these probably operated in a similar way. 384

385 Conversely the acetabulum is a more confined space in pelvic forms three and four: in the former

386 by expansion and increasing concavity, and in the latter by enclosure of the acetabulum dorsally

387 and ventrolaterally. The lateroventral acetabulum in pelvic form four results in the origins of the

388 femoral abducting musculature being orientated ventrally, particularly the M. ilio-femoralis and 
389 M. ilio-tibialis (Romer, 1923a; Hutchinson \& Gatesy, 2000). While the lever arm of this

390 musculature would be increased when the femur is held close to the sagittal plane, it would be

391 similarly decreased when held towards the coronal plane. This suggests that the capacity for

392 sprawling gait was diminished in pelvic form four.

393

394 Fundamental to these modifications, however, is the expansion of associated ventral elements of 395 the pelvic girdle in the Early Eocene species. This extends the lever arms of muscle groups

396 involved in both the stance and swing phases and support of the body against abduction induced

397 by gravity. The posterior expansion of the ischial arch extends the M. ischio trochantericus,

398 branches of the M. adductor femoris, and third branch of the M. pubo-ischio femoralis externus.

399 Expansion of the pubis extends the first and second branches of the M. pubo-ischio femoralis

400 externus (Romer, 1923a; Romer, 1923b). The extent of the rugosity on the pubis in pelvic form

401 two indicates marked development of the second branch. Ventral migration of the transverse

402 processes on the ilium similarly extends the medial musculature of the ilium posteriorly, and

403 excludes the pubo-ischio femeralis internus from the posterior medioventral surface of the ilium

404 (Romer, 1923a; Romer, 1923b). It is possible that origin of this muscle on the ilium was

405 eliminated entirely or at least much of its posterior extent reduced. It is also possible that it

406 migrated ventrally as well onto the anteroposteriorly expansive bridge between the peduncles of

407 the ischium. The exception is the ischium of pelvic form three. Despite close morphological

408 similarity with the apparently derived pelvic form four, pelvic form three's ventral musculature

409 would appear to have converged on that of crown group crocodylids. This further supports a

410 second radiation event, but one with a morphological fuse that extended back to an earlier

411 Eocene radiation, as the source of the Oligo-Miocene pelvic forms. 
412

413 Similar morphological diversification in the pectoral girdle appears concomitant with that of the

414 pelvic girdle. Eocene fossils, likely pertaining to Kambara (Figs. 8A-B), may again represent the

415 plesiomorphic condition for mekosuchines. The proportions are very similar to those found in

416 modern crocodilians. By the Oligo-Miocene, both highly gracile and robust elements had

417 developed, resulting in a similar division between girdles that retained more typically crocodilian

418 proportions (Fig. 8E) and those that display a distinct alteration in the muscle origins of the

419 articulating limb (Figs. 8F-I). The proportionally longer distal blade of the scapula in NMV

420 P227038, NMV P228623 and NMV P252359 (Figs. 8F-H), results in an increase in cross-

421 sectional area and length of the lever arm which would be important in the main stance phase

422 involving the stabilising musculature of the humerus. These muscles would include the M. teres

423 major, M. deltoideus scapularis and M. subscapularis (Meers, 2003). The M. coracobrachialis

424 brevis ventralis should be included among these if the distal blade of the coracoid was similarly

425 lengthened. In contrast with the pelvic girdle, however, the evolution of the articular surface of

426 the pectoral girdle appears to be more conservative. The glenoid is directed at the same angle to

427 the proximal head in the coronal plane in later Oligo-Miocene materials, the only variation being

428 the somewhat wider glenoid facet on the gracile coracoid QM F57912 (Fig. 8I). This potentially

429 allowed a greater range of motion of the humerus but this is difficult to tell without the proximal

430 humeral head to enable detailed analysis of the articular surfaces.

431

432 Mekosuchines appear therefore to have undergone a diversification of locomotory strategy by the

433 Oligo-Miocene. This has interesting palaeoecological implications regarding mekosuchine

434 faunas of the Riversleigh World Heritage Area. Pelvic forms two, three and four are all found in 
435 possibly close temporal proximity at Golden Steph and Ringtail Sites in Riversleigh's Faunal

436 Zone $\mathrm{C}$ assemblage. Ringtail Site notably preserves a diverse set of mekosuchine species in

437 apparent sympatry (Willis 1993, 2001). A distinct division of cranial shapes is also present

438 allowing for the niche specialisation of prey (Willis, 2001). Locomotory diversification suggests

439 another dimension of specialisation that complements cranial divisions, potentially allowing the

440 same prey divisions to be pursued in both semi-aquatic and fully terrestrial hunting ranges.

\section{Conclusions}

443 Diversification of cranial morphology in mekosuchine crocodiles between the Eocene and

444 Oligo-Miocene was matched by similar diversity in their pectoral and pelvic girdles. Assuming

445 that Eocene Kambara species exhibit the plesiomorphic state of the mekosuchine pelvis, it is

446 similar to that in extant gavialids and alligatorids. More specialised forms similar to crown group

447 crocodylids apparently developed secondarily by the Oligo-Miocene. One lineage developed a

448 progressively enclosed acetabulum and laterally expanded iliac crest. With elongation of

449 elements of the pubis and ischium, the line of action of the femur in these pelves shifted ventrally

450 towards the sagittal plane. This notably resembles the organisation in pillar-erect

451 crocodylomorphs of the Mesozoic. Another lineage, by contrast, seems to have retained the

452 structure of the pelvis seen in modern crocodilians, suggesting that members of this lineage

453 would have exhibited a variable gait. There therefore appears to have been a diversification of

454 locomotory strategies in mekosuchine crocodiles during this time period in tandem with

455 diversification of cranial shape, suggesting this is an important dimension in the process of

456 speciation in crocodilians. If the pillar-erect lineage is referable to Quinkana it would be 
457 indicative of a greater focus on cursorial movement, and the terrestrial sphere, in agreement with 458 the derived features of the quinkanine cranium.

459

460 Acknowledgements

461 We thank S. Hocknull of the Queensland Museum, Brisbane, E. Fitzgerald of Museum Victoria,

462 Melbourne and J. Scanlon, of the Riversleigh Interpretive Centre, Mount Isa for access to 463 comparative materials. We thank A. Gillespie for expert preparation of the specimens described 464 here. We also thank the editor and reviewers for their constructive criticisms of drafts of the 465 manuscript.

466

467 References

468 Abdala V, Diogo R. 2010. Comparative anatomy, homologies and evolution of the pectoral and

469 forelimb musculature of tetrapods with special attention to extant limbed amphibians and

470 reptiles. Journal of Anatomy 217:536-573. DOI: 10.1111/j.1469-7580.2010.01278.x.

471

472 Archer M, Godthelp H, Hand SJ, Megirian D. 1989. Fossil mammals of Riversleigh, 473 northwestern Queensland: preliminary overview of biostratigraphy, correlation and 474 environmental change. Australian Zoologist 25:29-65. DOI: 10.7882/AZ.1989.001. 475

Archer M, Hand SJ, Godthelp H. 1991. Riversleigh: the story of animals in ancient rainforests 477 of inland Australia. Balgowlah: Reed.

478 
479 Benton MJ, Clark JM. 1988. Archosaur phylogeny and the relationships of the Crocodylia. In:

480 Benton MJ, ed. The phylogeny and classification of the tetrapods. Oxford: Clarendon, 295-338.

481

482 Black KH, Archer M, Hand SJ, Godthelp H. 2012. The rise of Australian marsupials: a

483 synopsis of biostratigraphic, phylogenetic, palaeoecologic and palaeobiogeographic

484 understanding. In: Talent JA, ed. Earth and Life: Global Biodiversity, Extinction Intervals and

485 Biogeographic Perturbations Through Time. Dordrecht: Springer, 983-1078.

486

487 Brochu CA. 1999. Phylogenetics, taxonomy, and historical biogeography of Alligatoroidea.

488 Journal of Vertebrate Paleontology 19:1-100. DOI: 10.1080/02724634.1999.10011201.

489

490

Brochu CA. 2003. Phylogenetic approaches toward crocodylian history. Annual Review of Earth

491 and Planetary Sciences 31:357-97. DOI: 10.1146/annurev.earth.31.100901.141308.

492

493

494

Brusatte SL, Benton MJ, Ruta M, Lloyd GT. 2008. The first 50 Myr of dinosaur evolution: macroevolutionary pattern and morphological disparity. Biology Letters 4: 733-736. DOI: 10.1098/rsbl.2008.0441.

496

497 Buchanan LA. 2009. Kambara taraina sp. nov. (Crocodylia, Crocodyloidea), a new Eocene 498 mekosuchine from Queensland, Australia, and a revision of the genus. Journal of Vertebrate 499 Paleontology 29:473-486. DOI: 10.1671/039.029.0220. 500 
501 Buckley GA, Brochu CA, Krause DW, Pol D. 2000. A pug-nosed crocodyliform from the Late

502 Cretaceous of Madagascar. Nature 405:941-944. DOI: 10.1038/35016061.

503

504 Chamero B, Buscalioni AD, Marugan-Lobon J. 2013. Pectoral girdle and forelimb variation in 505 extant Crocodylia: the coracoidhumerus pair as an evolutionary module. Biological Journal of 506 the Linnean Society 108:600-618. DOI: 10.1111/j.1095-8312.2012.02037.x. 507

Colbert EH. 1946. Sebecus, representative of a peculiar suborder of fossil crocodilian from

509 Patagonia. Bulletin of the American Museum of Natural History 87:217-270.

510

511 Gatesy SM. 1991. Hind limb movements of the American alligator (Alligator mississippiensis)

512 and postural grades. Journal of Zoology 224:577-588. DOI: 10.1111/j.1469-

513 7998.1991.tb03786.x.

514

515 Gmelin J. 1789. Linne Systema Naturae: Leipzig, Beer G. E.

516

517 Godthelp H, Archer M, Cifelli R, Hand SJ, Gilkeson CF. 1992. Earliest known Australian

518 Tertiary mammal fauna. Nature 356:514-516. DOI: $10.1038 / 356514 \mathrm{a} 0$.

519

520 Hecht MK, Archer M. 1977. Presence of xiphodont crocodilians in the tertiary and Pleistocene 521 of Australia. Alcheringa 1:383-385. DOI: 10.1080/03115517708527772. 
523 Henstridge DA, Missen DD. 1982. Geology of oil-shale deposits within The Narrows graben,

524 Queensland, Australia. American Association of Petroleum Geologists Bulletin 66:719-731.

525

526 Hutchinson JR. 2006. The evolution of locomotion in archosaurs. Comptes Rendus

527 Paleovolume 5:519-530. DOI: 10.1016/j.crpv.2005.09.002.

528

529 Hutchinson JR, Gatesy SM. 2000. Adductors, abductors, and the evolution of archosaur

530 locomotion. Paleobiology 26:734-751. DOI: 10.1666/0094-

$5318373(2000) 026<0734:$ AAATEO $>2.0 . C O ; 2$.

532

533 Irmis RB. 2007. Axial skeleton ontogeny in the Parasuchia (Archosauria: Pseudosuchia) and its 534 implications for ontogenetic determination in archosaurs. Journal of Vertebrate Paleontology 535 27:350-361. DOI: 10.1671/0272-4634(2007)27[350:ASOITP]2.0.CO;2.

536

537 Mannion PD, Benson RBJ, Carrano MT, Tennant JP, Judd J, Butler RJ. 2015. Climate

538 constrains the evolutionary history and biodiversity of crocodylians. Nature Communications

539 6:1-9. DOI: $10.1038 /$ ncomms9438.

540

541 Markwick PJ. 1998. Crocodilian diversity in space and time: the role of climate in paleoecology 542 and its implication for understanding K/T extinctions. Paleobiology 24:470-497.

543 DOI: 10.1668/0003-1569(2001)041[0564:CSISAT]2.0.CO;2.

544 
545 Meers MB. 2003. Crocodylian forelimb musculature and its relevance to Archosauria. The

546 Anatomical Record Part A 274A:891-916. DOI: 10.1002/ar.a.10097.

547

548 Megirian D. 1994. A new species of Quinkana Molnar (Eusuchia: Crocodylidae) from the

549 Miocene Camfield beds of Northern Australia. The Beagle, Records of the Northern Territory

550 Museum 11:145-166.

551

552 Megirian D, Murray PF, Willis PMA. 1991. A new crocodile of the gavial ecomorph

553 morphology from the Miocene of Northern Australia. The Beagle, Records of the Northern

554 Territory Museum 8:135-158.

555

556

Megirian D, Prideaux GJ, Murray PF, Smit N. 2010. An Australian land mammal age biochronological scheme. Paleobiology 36:658-671. DOI: 10.1666/09047.1

558

Molnar RE, Worthy T, Willis PMA. 2002. An extinct Pleistocene endemic mekosuchine 560 crocodylian from Fiji. Journal of Vertebrate Paleontology 22:612-628. DOI: 10.1671/0272561 4634(2002)022[0612:AEPEMC]2.0.CO;2.

Oaks JR. 2011. A time-calibrated species tree of Crocodylia reveals a recent radiation of the 564 true crocodiles. Evolution 65:3285-3297. DOI: 10.1111/j.1558-5646.2011.01373.x.

565

567 Jinnah ZA, Ridgely R, Ngasala SE, Temba J. 2010. The evolution of mammal-like 
568 crocodyliforms in the Cretaceous period of Gondwana. Nature 466:748-751. DOI:

$56910.1038 /$ nature09061.

570

571 Page RDM. 1996. TREEVIEW: An application to display phylogenetic trees on personal

572 computers. Computer Applications in the Biosciences 12:357-358. DOI:

573 10.1093/bioinformatics/12.4.357.

574

575 Parrish JM. 1986. Locomotor adaptations in the hindlimb and pelvis of the Thecodontia.

576 Hunteria 1:1-36.

577

578 Parrish JM. 1987. The origin of crocodilian locomotion. Paleobiology 13:396-414.

579 DOI: $10.1017 / \mathrm{S} 0094837300009003$.

580

581 Pol D, Leardi JM, Lecuona A, Krause M. 2012. Postcranial anatomy of Sebecus icaeorhinus

582 (Crocodyliformes, Sebecidae) from the Eocene of Patagonia. Journal of Vertebrate Paleontology

583 32:328-354. DOI: 10.1080/02724634.2012.646833.

584

585 Puertolas-Pascual E, Blanco A, Brochu CA, Canudo JI. 2016. A review of the Late

586 Cretaceous-early Paleogene crocodylomorphs of Europe: Extinction patterns across the K-PG

587 boundary. Cretaceous Research 57:565-590. DOI: 10.1016/j.cretres.2015.08.002. 
589 Reilly SM, Elias JA. 1998. Locomotion in Alligator mississippiensis: kinematic effects of speed 590 and posture and their relevance to the sprawling-to-erect paradigm. The Journal of Experimental 591 Biology 201:2559-2574.

592

593 Romer AS. 1923a. Crocodilian pelvic muscles and their avian and reptilian

594 homologues. Bulletin of the American Museum of Natural History 48:533-552.

595

596

597

Romer AS. 1923b. The pelvic musculature of saurischian dinosaurs. Bulletin of the American Museum of Natural History 48:605-617.

598

Salisbury SW, Willis PMA. 1996. A new crocodylian from the early Eocene of south-eastern 600 Queensland and a preliminary investigation of the phylogenetic relationships of crocodyloids. 601 Alcheringa 20:179-226. DOI: 10.1080/03115519608619189.

602

Schachner ER, Manning PL, Dodson P. 2011. Pelvic and hindlimb myology of the basal 604 archosaur Poposaurus gracilis (Archosauria: Poposauroidea). Journal of Morphology 272:1464605 1491. DOI: 10.1002/jmor.10997.

606

607 Schneider JG. 1801. Historiae Amphibiorum Naturalis Et Literariae. Jena: Fromann F. 608

609 Schwarz D, Frey E, Martin T. 2006. The postcranial skeleton of the Hyposaurinae 610 (Dyrosauridae; Crocodyliformes). Palaeontology 49:695-718. DOI: 10.1111/j.1475611 4983.2006.00563.x. 
612

613 Sereno PC. 1991. Basal Archosaurs: phylogenetic relationships and functional implications.

614 Journal of Vertebrate Paleontology 11:1-53. DOI: 10.2307/3889336.

615

616 Sereno PC, Larsson HCE. 2009. Cretaceous crocodyliforms from the Sahara ZooKeys 28:1-

617 143. DOI: 10.3897/zookeys.28.325.

618

619 Sertich JJW, Groenke JR. 2010. Appendicular skeleton of Simosuchus clarki

620 (Crocodyliformes: Notosuchia) from the Late Cretaceous of Madagascar. Journal of Vertebrate

621 Paleontology 30S1:122-153. DOI: 10.1080/02724634.2010.516902.

622

623 Simpson GG. 1937. New reptiles from the Eocene of South America. American Museum 624 Novitates 927:1-3.

625

626 Stein M, Hand SJ, Archer M. 2016. A new crocodile displaying extreme constriction of the 627 mandible, from the late Oligocene of Riversleigh, Australia. Journal of Vertebrate Paleontology 628 36:e1179041. DOI: 10.1080/02724634.2016.1179041

629

630 Stein M, Salisbury SW, Hand SJ, Archer M and Godthelp H. 2012. Humeral morphology of

631 the early Eocene mekosuchine crocodylian Kambara from the Tingamarra Local Fauna

632 southeastern Queensland, Australia. Alcheringa 36:473-486. DOI:

$63310.1080 / 03115518.2012 .671697$.

634 
635 Stubbs TL, Pierce SE, Rayfield EJ and Anderson PSL. 2013. Morphological and

636 biomechanical disparity of crocodile-line archosaurs following the end-Triassic extinction.

637 Proceedings of the Royal Society B 280:20131940. DOI: 10.1098/rspb.2013.1940.

638

639 Swofford DL. 2003. PAUP* phylogenetic analysis using parsimony (*and other methods).

640 Version 4. Sunderland: Sinauer Associates. DOI: 10.1111/j.0014-3820.2002.tb00191.x

641

642 Toljagic O, Butler RJ. 2013. Triassic-Jurassic mass extinction as trigger for the Mesozoic

643 radiation of crocodylomorphs. Biology Letters 9. DOI: 10.1098/rsbl.2013.0095.

644

645 Travouillon KJ, Archer M, Hand SJ, Godthelp H. 2006. Multivariate analyses of Cenozoic

646 mammalian faunas from Riversleigh, north-western Queensland. Alcheringa 30:323-349. DOI:

$647 \quad 10.1080 / 03115510609506871$.

648

649 Wilberg EW. 2017. Investigating patterns of crocodyliform cranial disparity through the

650 Mesozoic and Cenozoic. Zoological Journal of the Linnean Society. DOI:

651 10.1093/zoolinnean/zlw027.

652

653 Willis PMA. 1993. Triliphosuchus rackhami, gen. et sp. nov., a new crocodilian from the early

654 Miocene limestones of Riversleigh, northwestern Queensland. Journal of Vertebrate

655 Paleontology 13:90-98. DOI: 10.1080/02724634.1993.10011489.

656 
657 Willis PMA. 1997a. A review of fossil crocodilians from Australia. Australian Zoologist

658 30:287-298. DOI: 10.7882/AZ.1997.004.

659

660 Willis PMA. 1997b. New crocodilians from the late Oligocene White Hunter Site, Riversleigh, 661 north-western Queensland. Memoirs of the Queensland Museum 41:423-438.

662

663 Willis PMA. 2001. New crocodilian material from the Miocene of Riversleigh (northwestern 664 Queensland, Australia). In: Grigg GC, Seebacher F, Franklin CE eds. Crocodilian biology and 665 evolution. Sydney: Surrey Beatty and Sons, 64-74.

666

667 Willis PMA, Molnar RE. 1991. A new middle Tertiary crocodylian from Lake Palakarinna, 668 South Australia. Records of the South Australian Museum 25:39-55.

669

Willis PMA, Molnar RE. 2008. A longirostrine crocodile from the early Tertiary of South eastern Queensland. Alcheringa 15:229-233. DOI: 10.1080/03115519108619019.

672

Willis PMA, Molnar RE, Scanlon JD. 1993. An early Eocene crocodilian from Murgon, 674 southeastern Queensland. Kaupia: Darmstadter Beitrage zur Naturgeschichte 3:25-32.

675

Willis PMA, Murray PF, Megirian D. 1990. Baru darrowi gen. et sp. nov., a large broadsnouted crocodyline (Eusuchia: Crocodylidae) from mid-Tertiary freshwater limestones in 678 Northern Australia. Memoirs of the Queensland Museum 29:521-540.

679 
680 Woodhead J, Hand SJ, Archer M, Graham I, Sniderman K, Arena DA, Black KH,

681 Godthelp H, Creaser P, Price E. 2016. Developing a radiometrically-dated chronologic

682 sequence for Neogene biotic change in Australia, from the Riversleigh World Heritage Area of

683 Queensland. Gondwana Research 29:153-167. DOI: 10.1016/j.gr.2014.10.004.

684

685 Worthy TH, Tennyson AJD, Archer M, Musser AM, Hand SJ, Jones C, Douglas BJ,

686 McNamara JA, Beck RMD. 2006. Miocene mammal reveals a Mesozoic ghost lineage on

687 insular New Zealand, southwest Pacific. Proceedings of the National Academy of Sciences

688 103:19419-19423. DOI: 10.1073/pnas.0605684103. 
Figure 1

Locality map.

Map showing referenced fossil localities noted in text. Scale bar equals 500 kilometres. Map data (c) 2016 GBRMPA, Google.

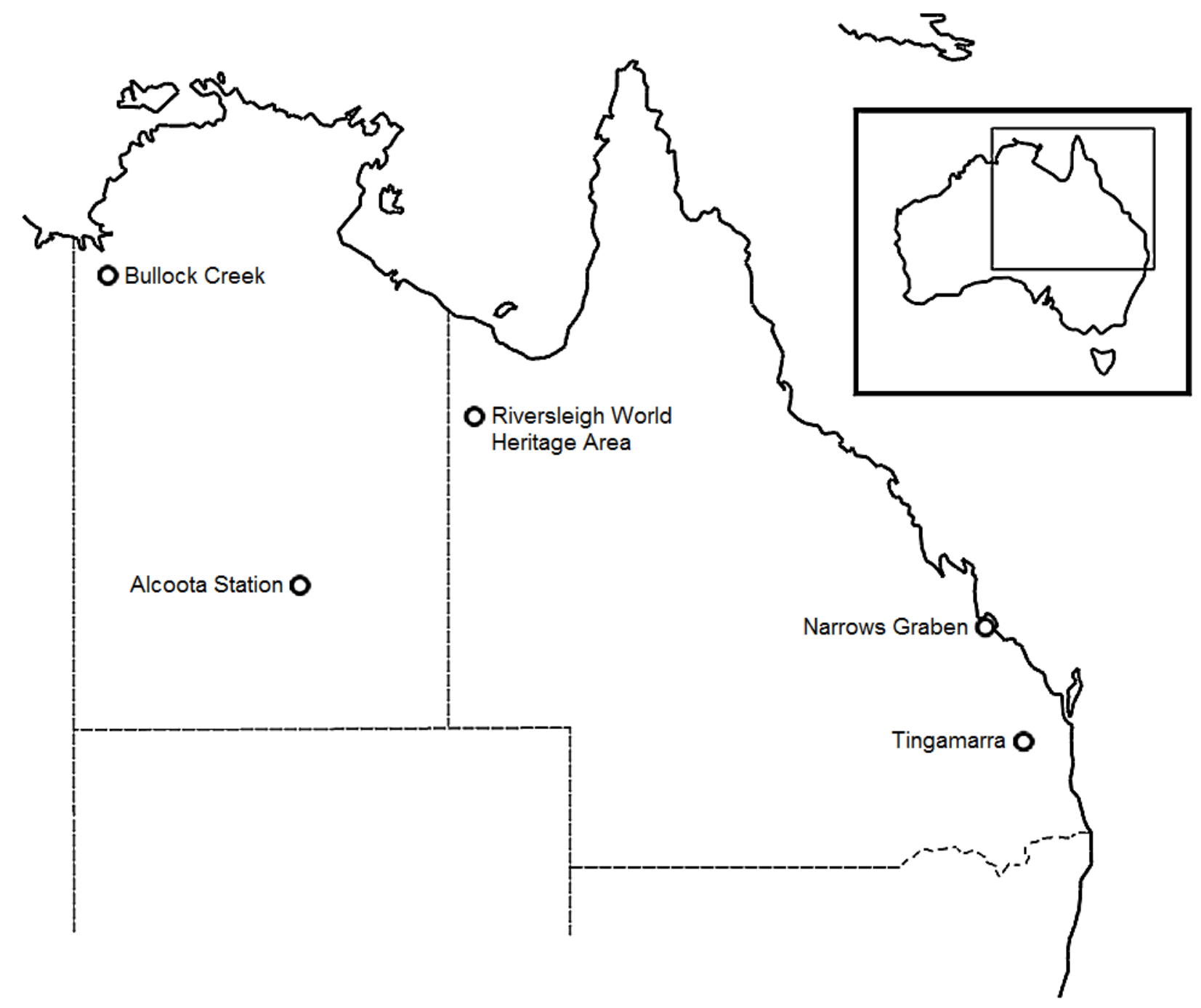




\section{Figure 2}

The modern crocodilian pelvic girdle.

Pelvic girdle of Crocodylus porosus Schneider, 1801, (AM R131835) illustrating terminology used in this study. $1^{\text {st }}$ sac. vert., first sacral vertebrae; $2^{\text {nd }}$ sac. vert., second sacral vertebrae; ace., acetabulum; ace. perf., acetabular perforation; il., ilium; il. cr., iliac crest; il. pub. ped., pubic peduncle of the ilium; il. is. ped., ischial peduncle of the ilium; is., ischium; is. ant. ped., anterior peduncle of the ischium; is. dist. bl., distal blade of the ischium; is. ped. br., peduncle bridge of the ischium; is. post. ped., posterior peduncle of the ishium; M. il. caud., attachment site for the musculus ilioischio caudalis; M. pub. tib., attachment for the musculus puboischio tibialis; postace. pro., postacetabular process; preace. pro., preacetabular process; pub., pubi. Scale bar equals five centimetres. 


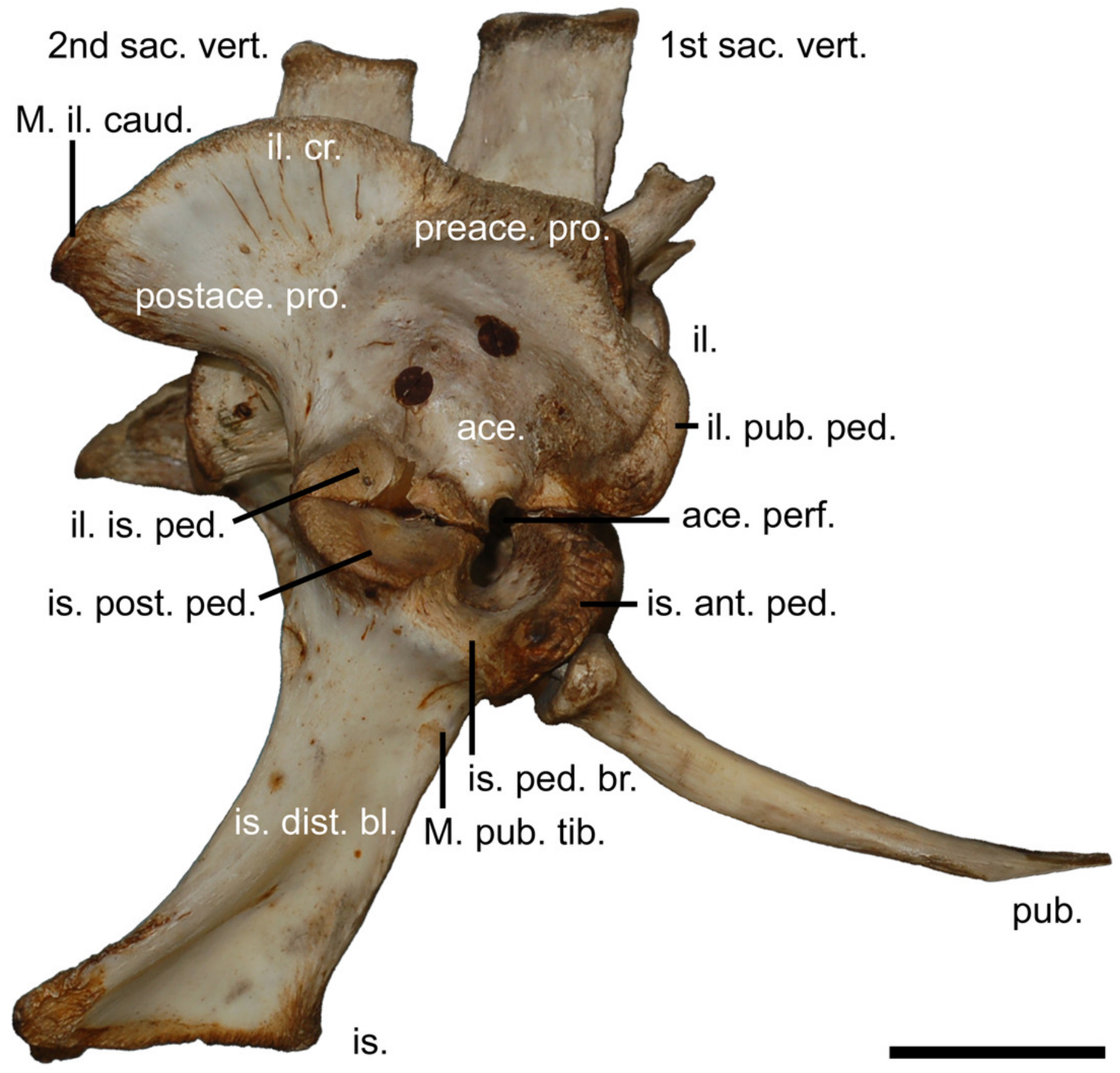


Figure 3

Results of parsimony analysis.

Majority rule consensus trees resulting from A, parsimony analysis of selected pelvic characters, B, bootstrap analyses of selected pelvic characters. Trees are rooted with the Gavialis outgroup and pelvic forms are highlighted. Illustrated in TreeView (Page, 1996).
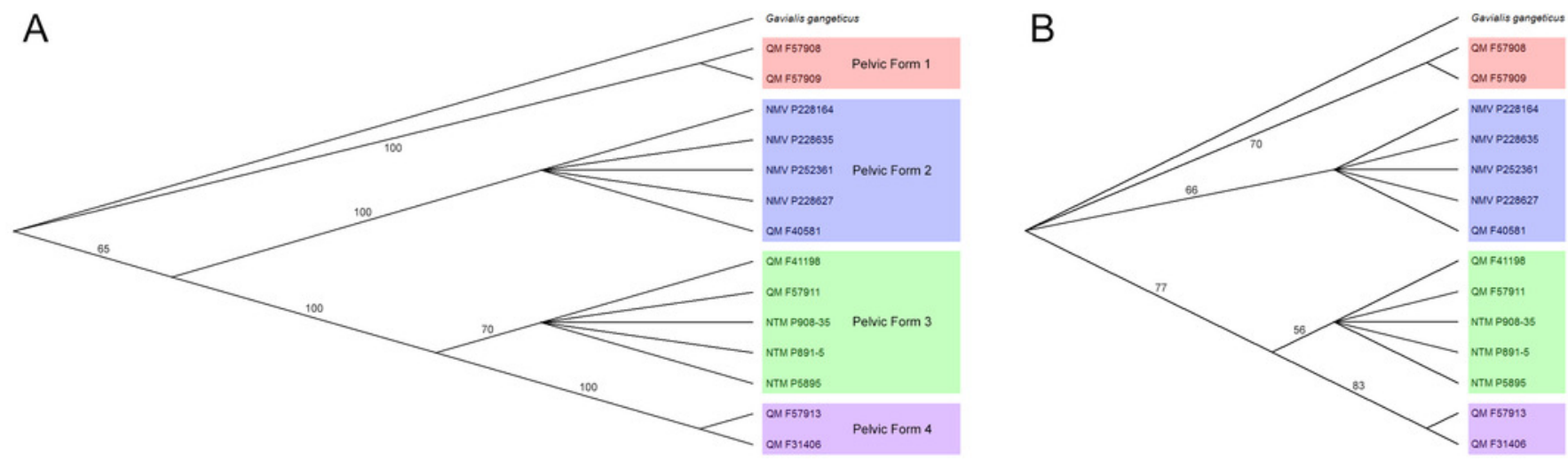


\section{Figure 4}

Pelvic form one.

QM F57908 in A, lateral B, medial and C, posterior views, QM F57909 in D, lateral view, QM F57910 in E, lateral view, QM F54537 in F, lateral G, medial and H, anterior views. All scale bars equal two centimetres. 

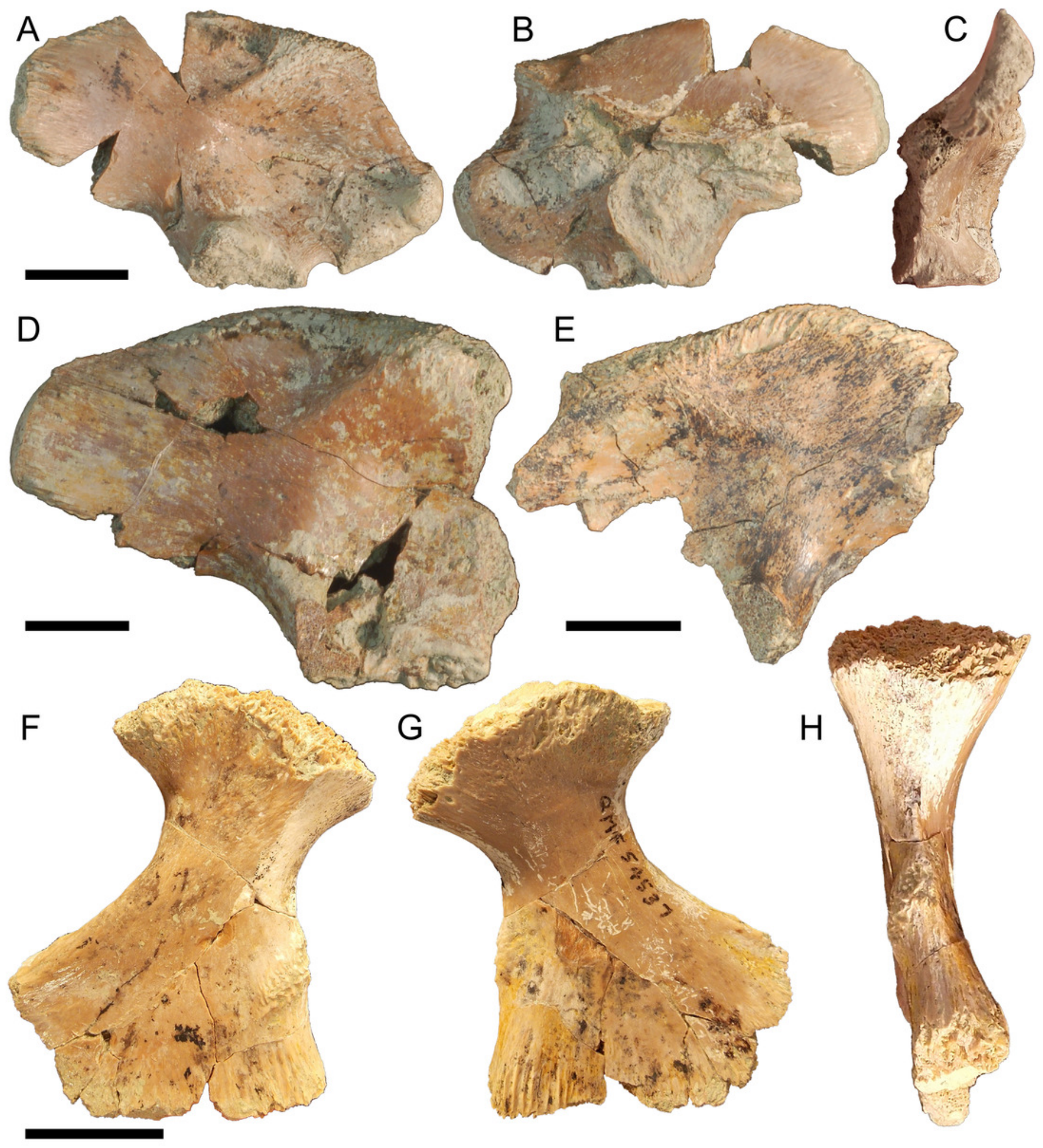


\section{Figure 5}

Pelvic form two.

NMV P228164 in A, lateral B, medial and C, dorsal views, NMV P228635 in D, lateral view, NMV P252361 in E, lateral view, NMV P228627 in F, lateral view, QM F40581 in G, lateral view, NMV P228615 in F, dorsal view, All scale bars equal two centimetres. 


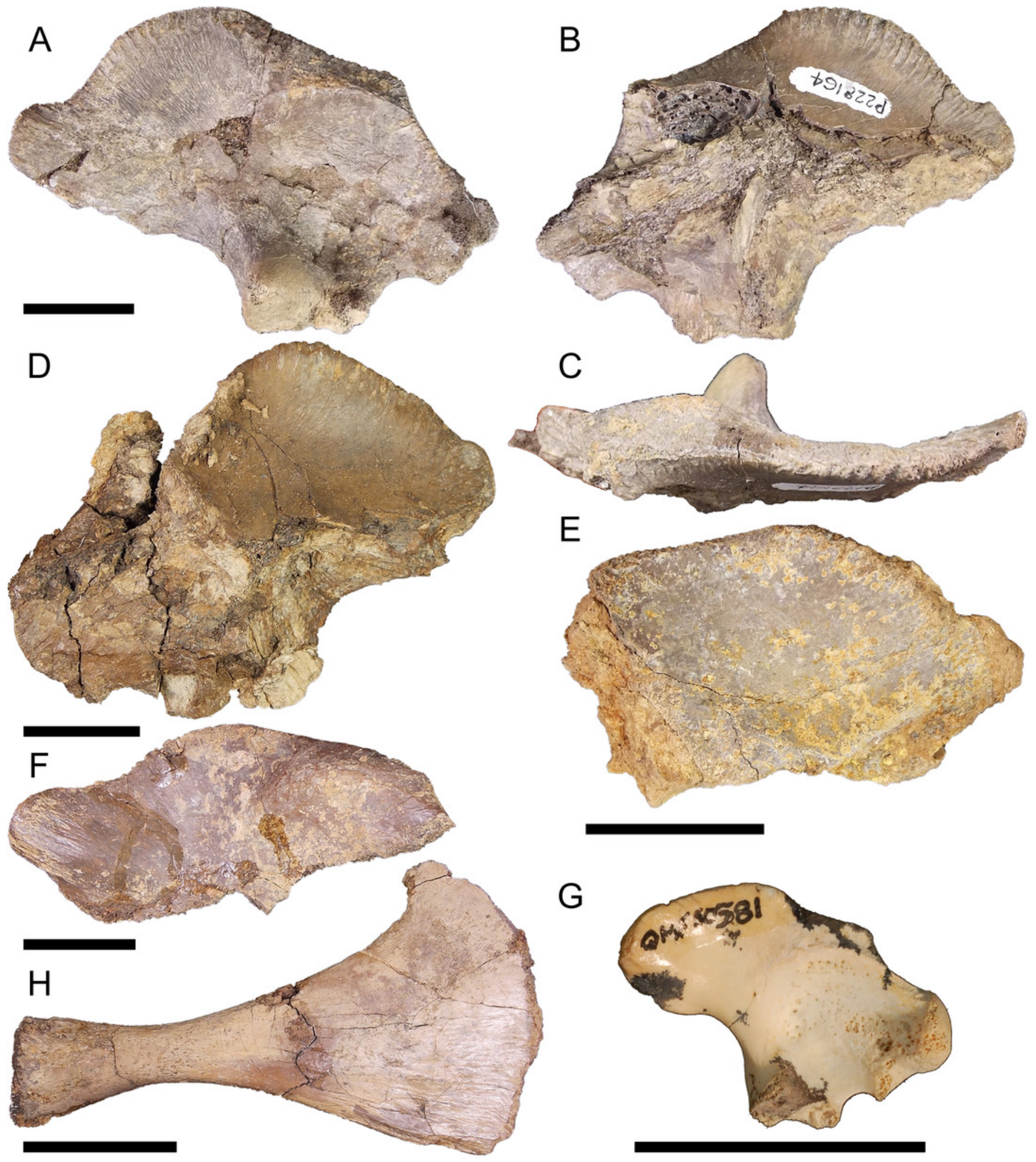




\section{Figure 6}

Pelvic form three.

QM F41198 in A, lateral B, medial C, posterior views, QM F57911 in D, lateral view, NTM P908-35 in E, lateral view, NTM P891-5 in F, lateral view, NTM P5895 in G, lateral view, NTM P906-23 in H, lateral view, NTM P8695-272 in I, lateral view. All scale bars equal two centimetres.

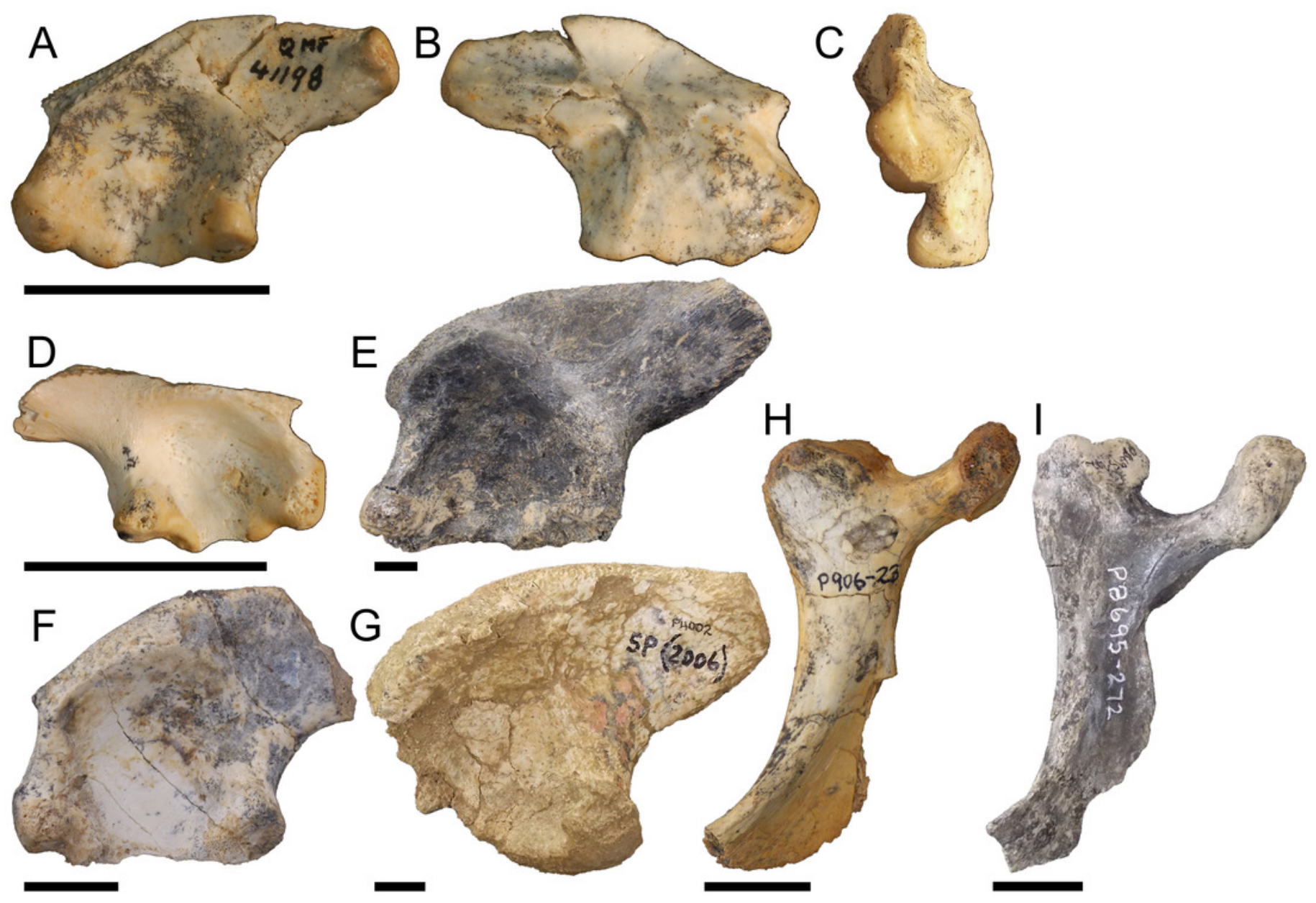


Figure 7

Pelvic form four.

QM F57913 in A, lateral B, medial C posterior views, pubis in D, dorsal and E, lateral views, QM F31406 in F, lateral view, QM F57914 in G, lateral view. All scale bars equal two centimetres.

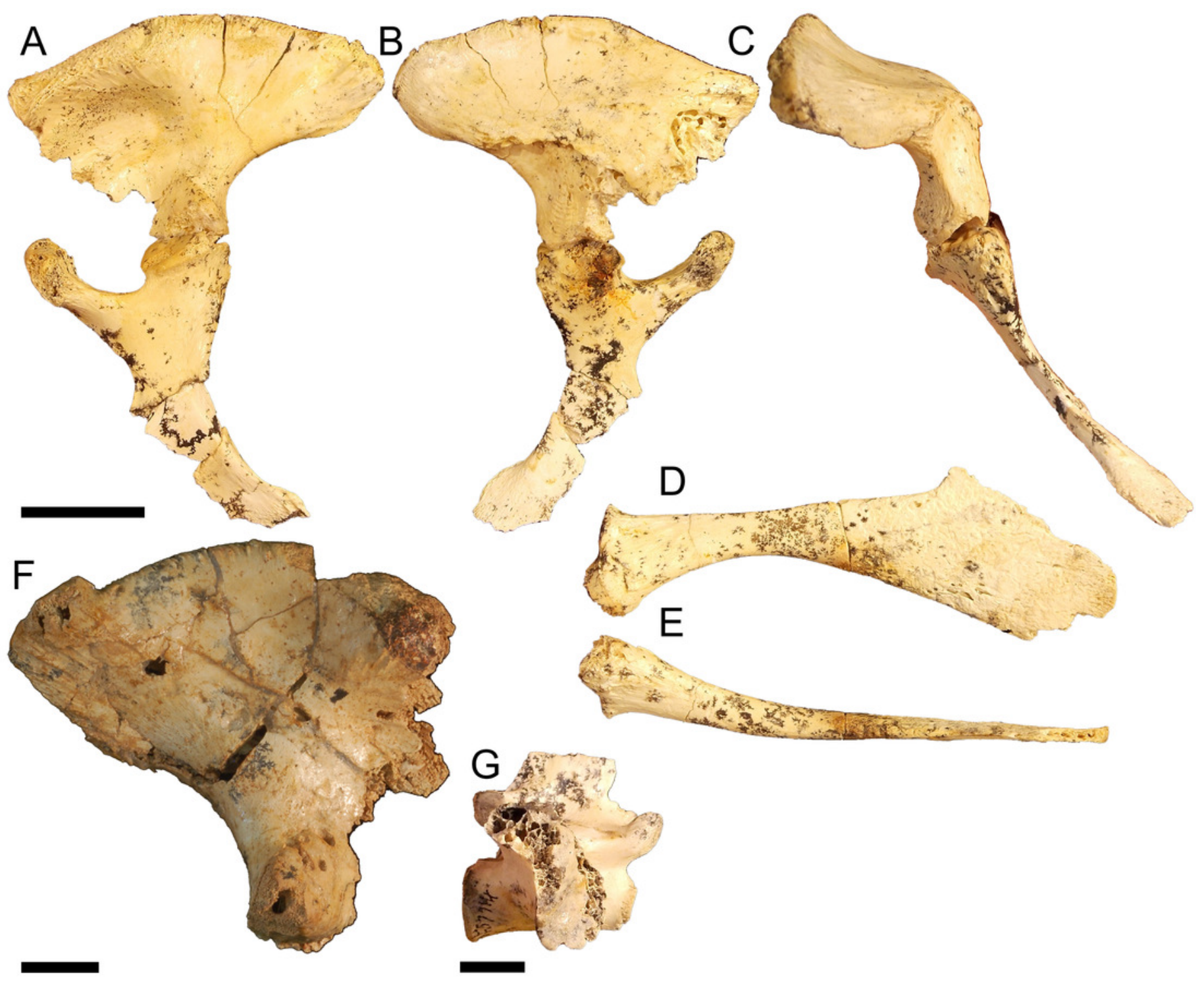




\section{Figure 8}

Pectoral girdle material.

QM F23586 in A, lateral view, QM F54533 in B, lateral view, NMV P227803 in C, lateral view, NMV P252360 in D, lateral view, NTM P895-139 in E, lateral view, NMV P228623 in F, lateral view, NMV P227028 in G, lateral view, NMV P252359 in H, anterior view, and QM F57912 in I, lateral view. All scale bars equal two centimetres.
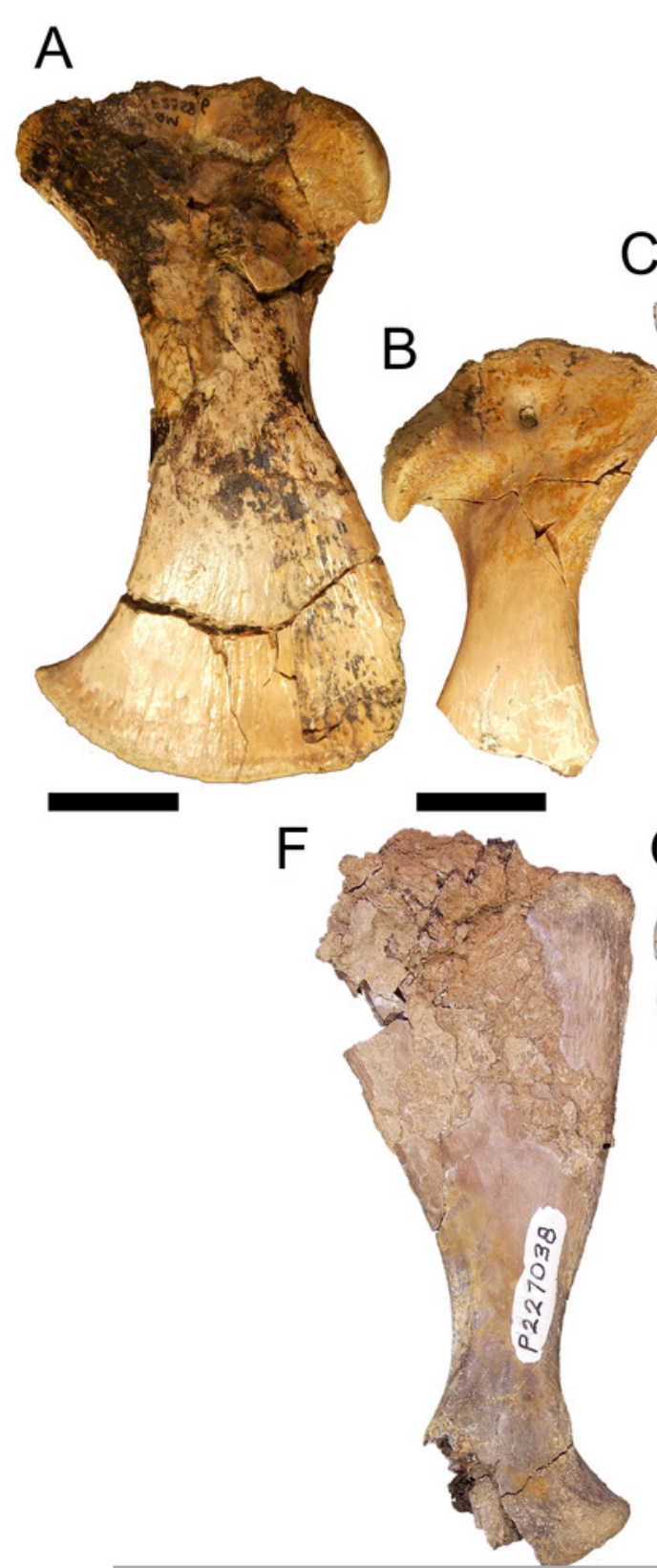

C

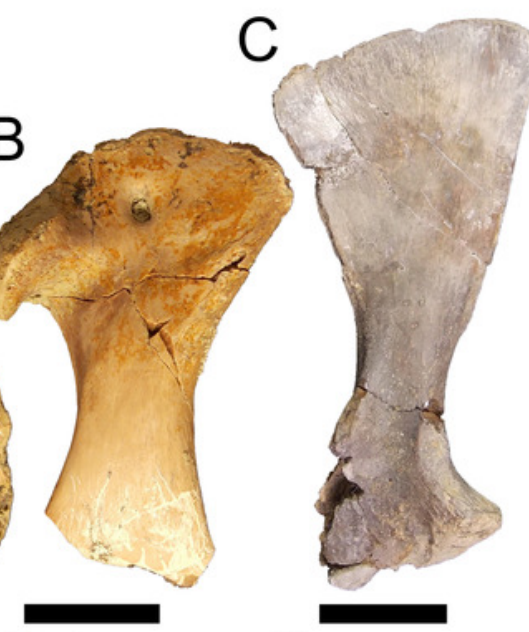

G

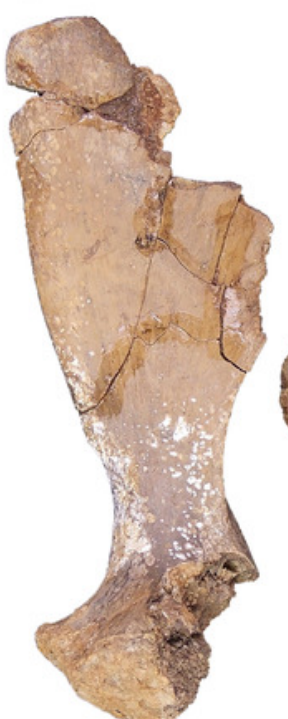

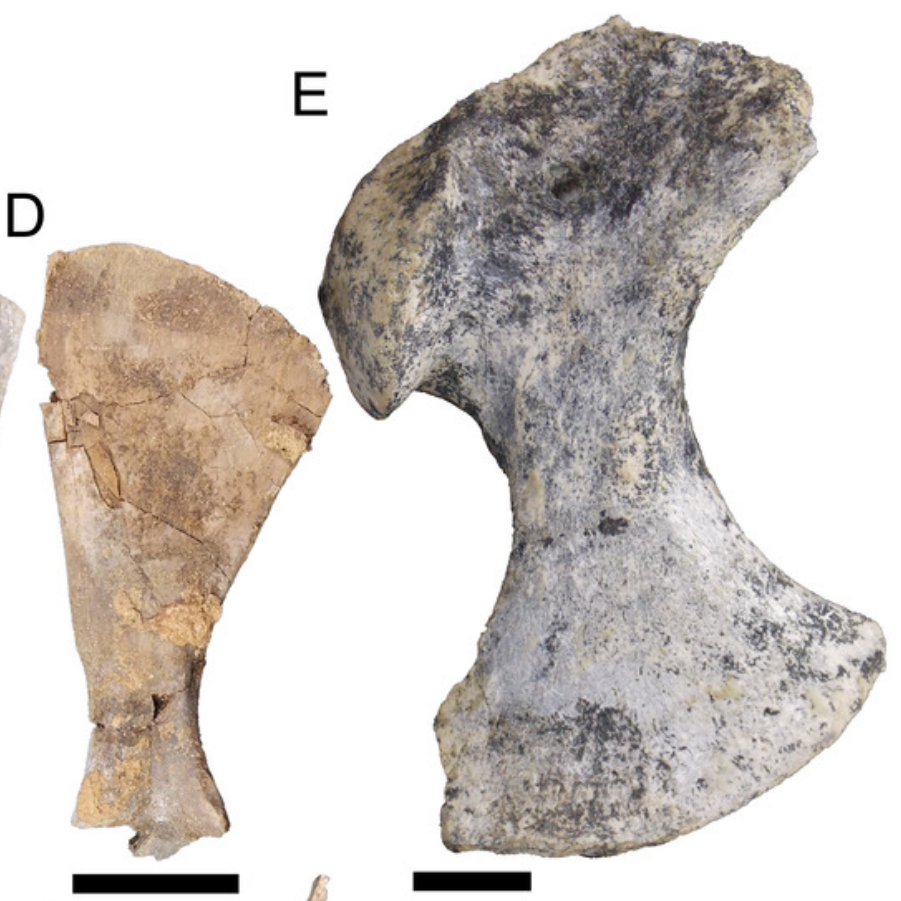

